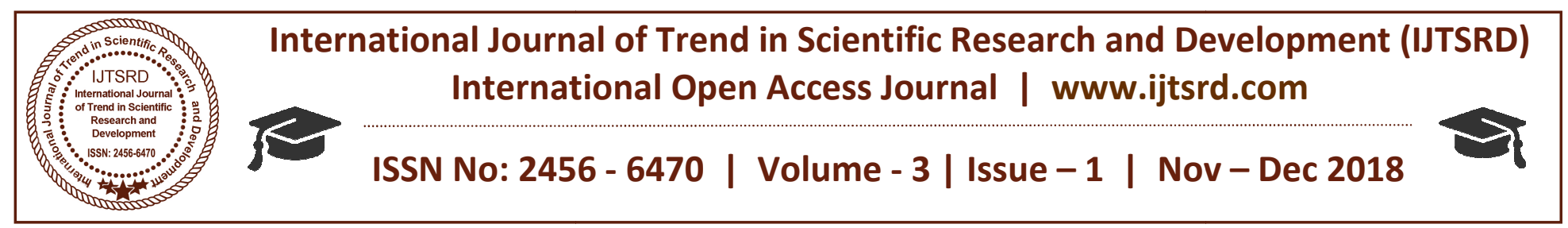

\title{
A Study of Mental Health Among Urban and Rural College Students
}

\author{
Dr. Ramesh D. Waghmare \\ Assistant professor, Godawari College Ambad, Jalna, Maharasatra, India
}

\section{ABSTRACT}

Mental Health is "the emotional and spiritual resilience which enables us to enjoy life and survive pain, suffering and disappointment. It is a positive sense of well being and an underlying belief in our and others dignity and worth. It is influenced by our experience and our genetic inheritance." The main objective of the present study is to examine the Mental Health's viz. Positive Self-Evaluation, Perception of Reality, Integration of Personality, Autonomy, Group Oriented Attitudes, Environment Mastery among Urban and Rural College Students. A sample of 100 participants 50 Urban (25 Male and 25 Female) \& 50 Rural (25 Male and 25 Female)) was drawn randomly from the population. Mental health inventory developed by Dr. Jagdish \& Dr. A.K. Srivastava (1983) was used for data collection. Factorial design was used and data were analysis by Mean, SD and ' $F$ ' values. Results show that 1) there is no significant difference between Urban and Rural College students with Mental Health dimension on Positive self Evaluation. 2) Rural College Students high Perception of Reality than Urban College Students. 3) There is no significant difference between Urban and Rural College students with Mental Health dimension on Integration of Personality.4) Rural college Students high Autonomy than Urban College Students. 5) There is no significant difference between Urban and Rural College students with Mental Health dimension on Group Oriented Attitudes. 6) There is no significant difference between Urban and Rural College students with Mental Health dimension on Environment Mastery. 7) There is no significant differences between Male and Female college students on Mental Health.

KEY WORDS: Living of Area, Positive SelfEvaluation, Perception of Reality, Integration of Personality, Autonomy, Group Oriented Attitudes, Environment Mastery

\section{INTRODUCTION}

Mental health is about the ability to work and study to realize your full potential, cope with day-to-day life stresses, be involved in your community, and live your life in a free and satisfying way. A person who has good mental health has good emotional and social well-being and the capacity to cope with change and challenges.

The World Health Organization (WHO) defines mental health as a state of well being in which every individual realizes his or her own potential, tries to cope up with the normal stresses of life, tries to work productively and fruitfully and is capable to make worthy contribution in life.

The World Health Organization (2001) define mental health as " a state of well being in which the individual realize his or her own abilities, can cope with the normal stress of life, can work productively and fruitfully, and is able to make contribution to his or her community". There was no one official definition of mental health. Cultural difference, subjective assessment and competing professional theories all affect mental health definition. According to Kaplan (1971), "Mental Health involves a continuous adaptation to changing circumstances, a dynamic process where a living, reaching being striving to achieve a balance between internal demands and the requirements of a changing environment." Jahoda (1958) subdivided mental health into three domains: self-realization, in that individual is able to fully exploit their potential; sense of mastery over the environment; and sense of autonomy, i.e. ability to identify, confront, and solve problems.

Mental health is the ability to make adequate adjustments to the environment on the plane of reality. It is as the ability to balance feelings, desires, ambitions and ideals in one's daily living. It means 
the ability to face and accept the realities of life. Mental health is a term used describes how well the individual is adjusted to the demands and opportunities of life. It is very broad term which includes physical, mental, emotional and social aspects of adjustment.

\section{Review of literature:-}

Morab, and at all, (2014) indicated that there was no significant difference between rural male and female elderly on mental health, positive self evaluation, perception of reality, integration of personality, autonomy, group oriented attitude, environmental mastery.

Vijay Kumar and at all, (Nov.2013) indicated that There is no significant difference between Urban and rural pupil teachers in the mental health with Positive Self-Evaluation, Perception of Reality, Integration of Personality, Autonomy, Group Oriented Attitudes, Environment Mastery and mental health.

\section{Statement of the problem}

"A Study of Mental Health among Urban and Rural College Students"

\section{Objectives:-}

The following are main objectives of the present study.

1. To examine Mental Health of Urban \& Rural college going Students.

\section{Hypothesis:}

1. There is no significant difference between Urban \& Rural College going Students with Mental Health dimension on Positive Self-Evaluation.
2. There is no significant difference between Urban \& Rural College going Students with Mental Health dimension on, Perception of Reality.

3. There is no significant difference between Urban \& Rural College going Students with Mental Health dimension on Integration of Personality.

4. There is no significant difference between Urban \& Rural College going Students with Mental Health dimension on Autonomy.

5. There is no significant difference between Urban \& Rural College going Students with Mental Health dimension on Group Oriented Attitudes.

6. There is no significant difference between Urban \& Rural College going Students with Mental Health dimension on Environment Mastery.

7. There is no significant difference between Urban \& Rural College going Students on Mental Health.

\section{Methods}

\section{Participants}

The present study sample go was selected from college students of Ambad City Dist. Jalna in Maharashtra. To select the sample Living of Area in which students study of College Students were considered as per independent variable taken in this research stratified random sampling method was employed to select the unit of sample. Total sample of present study 100 college students, in which 50 were Urban College Students (25 Male and 25 Female) and 50 Rural College Students (25 Male and 25 Female) The subject selected in this sample will be used in the age group of 18 years to 21 years (Mean - 19.16, SD2.01.) and Ratio 1:1.

\section{Research Design}

Factorial design used in the present study.

\begin{tabular}{|c|c|c|l|}
\multicolumn{4}{|c|}{ Variables of the Study } \\
\hline Variable & Type of variable & Sub. Variable & \multicolumn{1}{c|}{ Name of variable } \\
\hline Living of Area & Independent & 02 & 1) Urban 2) Rural \\
\hline & & & $\begin{array}{l}\text { 1) Positive Self-Evaluation } \\
\text { Mental Health }\end{array}$ \\
& Dependent & 06 & $\begin{array}{l}\text { 3) Integration of Reality } \\
\text { 4) Autonomy } \\
\text { 5) Group Oriented Attitudes }\end{array}$ \\
& & $\begin{array}{l}\text { 6) Environment Mastery } \\
\text { 6) Entity }\end{array}$ \\
\hline
\end{tabular}

\begin{tabular}{|c|c|l|}
\multicolumn{3}{|c|}{ Instruments } \\
\hline Aspect & Name of the Test & \multicolumn{1}{c|}{ Author } \\
\hline Mental Health & Mental health inventory (1983) & $\begin{array}{l}\text { Dr. Jagdish } \\
\text { Dr. A.K. Srivastava }\end{array}$ \\
\hline
\end{tabular}




\section{Mental health inventory:}

Mental health inventory developed by Dr. Jagdish \& Dr. A. K. Srivastava(1983). This scale consist of 56 items based on 6 dimensions - (1) positive selfevaluation, (2) realistic perception, (3) integration of personality, (4) Autonomy, (5) group-oriented attitude, (6) environmental mastery. The scale has four response categories viz. always, often, rarely and never. The reliability and validity coefficients were found significant as the value of split-half

Reliability coefficient was $\mathrm{r}=0.73$ and validity i.e. construct validity was $\mathrm{r}=0.54$ which confirm the standardization of the scale.

\section{Operational definition \\ Mental health:}

Mental health is defined as person's ability to make positive self - evaluation, to perceive the reality, to integrate the personality, autonomy group oriented attitudes and environmental mastery.

\section{Positive Self-evaluation (PSE):}

It includes self confidence, self-acceptance, self identity, feeling of worthiness, realization of one's potentialities, etc.

\section{Perception of Reality (PR):}

It is related to perception free need distortion, absence of excessive fantasy and a broad outlook on the world.

\section{Integration of Personality (IP):}

It indicates balance of psychic forces in the individual and includes the ability to understand and to share other people's emotions, the ability to concentrate at work and interest in several activities.

\section{Autonomy (AUTNY):}

It includes stable set of internal standards for one "s action, dependence for own development upon own potentialities rather than dependence on other people.

\section{Group-oriented Attitude (GOA):}

It is associated with the ability to get along with others, work with others and ability to find recreation.

\section{Environmental Mastery (EM):}

It includes efficiency in meeting situation requirements, the ability to work and play, the ability to take responsibilities and capacity for adjustment.

\section{Procedures of data collection}

The following research methodology was used in the present study. The primary information was gathered by giving personal information from to each to each student. The students were called in a small group of 10 to 15 students. To fill the inventories subjects were given general instructions belongs to each scale. The students provided mental health inventory.

\section{Data analysis}

The data were analyzed as follows.

The Mean and SD with graphical representation for Living of Area (Urban and Rural College Students) on Mental Health was analyzed. A Factorial design was selected to adequate of statistical analysis of ANOVA in order to examine the roll of main as well as subsequently on student's Mental Health.

\section{Results and Discussion}

The analysis of data interpretation and discussion of the results are presented below.

Table No.01 Show the mean, SD and F value Living of Area on Positive self Evaluation

\begin{tabular}{|c|c|c|c|c|c|c|}
\hline Location & Mean & SD & N & DF & F & Sign \\
\hline Surban It & 25.10 & 6.60 & 50 & & & \\
$\begin{array}{c}\text { Students } \\
\text { Rural } \\
\text { Students }\end{array}$ & 24.84 & 6.38 & 50 & 98 & 0.49 & NS \\
\hline
\end{tabular}

(Critical value of "f" with df 98 at $0.01=3.94$ and at $0.05=6.90$ and NS-Not significant)

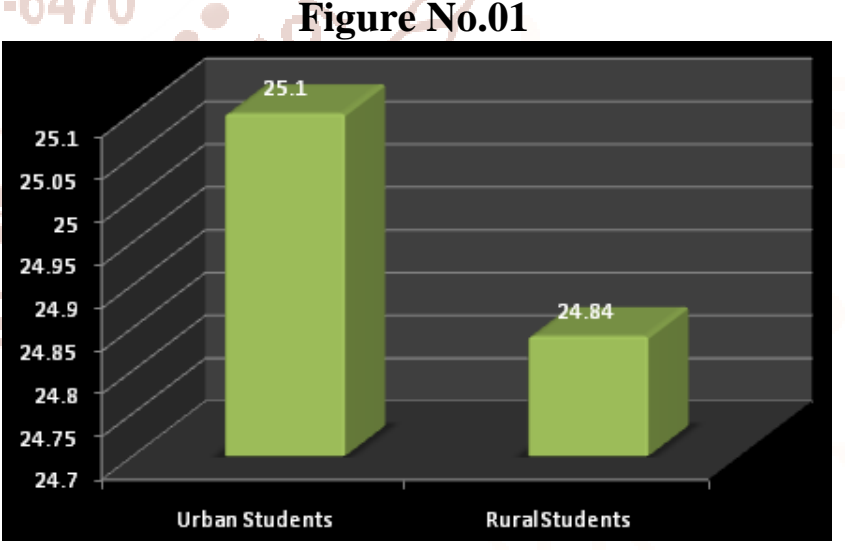

Observation of the table No.01 and Figure No.01 indicated that the mean value of two classified group seems to differ from each other on Positive self Evaluation. The mean and SD value obtained by the Urban college students 25.10, SD 6.60 and Rural College students was 24.84, SD 6.38, Both group ' $F$ ' ratio was 0.49 at a glance those Urban college student shows miner high score than Rural college students. 
In the present study was hypothesis related Positive self Evaluation and Living of Area. It was "There is no significant differences between Urban and Rural college students with Mental Health dimension on Positive self Evaluation. Living of Area effect represent the Positive self Evaluation was not significant ((F- 0.49, 1and 99, P-NS). This is not significant 0.01 and 0.05 levels because they obtained ' $F$ ' value are low than table values at 0.01 and 0.05 . In the present study was found that Urban and Rural college students not significant differences from Positive self Evaluation. The findings of the supported the hypothesis, they are hypothesis Accepted the present study. Its means that there is no significant difference between Urban and Rural College students with Mental Health dimension on Positive self Evaluation.

Table No.02 Show the mean, SD and F value
Living of Area on Perception of Reality
\begin{tabular}{|c|c|c|c|c|c|c|}
\hline Location & Mean & SD & N & DF & F & Sign \\
\hline $\begin{array}{c}\text { Urban } \\
\text { Students }\end{array}$ & 20.92 & 5.37 & 50 & & & \\
\hline $\begin{array}{c}\text { Rural } \\
\text { Students }\end{array}$ & 25.02 & 5.77 & 50 & & & \\
\hline
\end{tabular}

(Critical value of "f" with df 98 at $0.01=3.94$ and at $0.05=6.90$ and NS-Not significant)

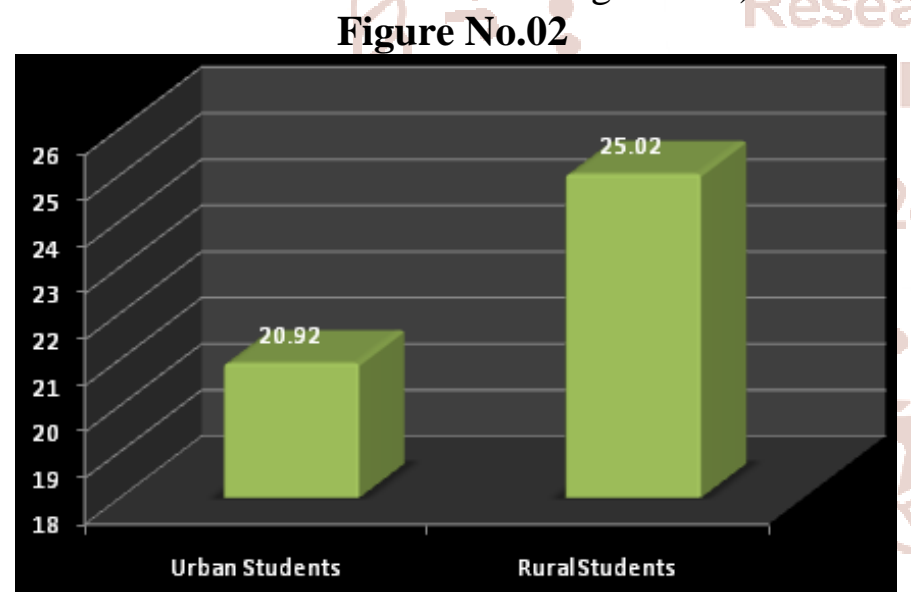

Observation of the table No.02 and Figure No.02 indicated that the mean value of two classified group seems to differ from each other on Perception of Reality. The mean and SD value obtained by the Urban college students 20.92, SD 5.37 and Rural College students was 25.02, SD 5.77, Both group ' $F$ ' ratio was 16.35 at a glance those Rural college student shows miner high score than Urban college students.

In the present study was hypothesis related Perception of Reality and Living of Area. It was "There is no significant differences between Urban and Rural college students with Mental Health dimension on Perception of Reality. Living of Area effect represent the Perception of Reality was not significant ((F16.35, 1 and 99, P-0.01). This is significant 0.01 and 0.05 levels because they obtained ' $\mathrm{F}$ ' value are high than table values at 0.01 and 0.05 . In the present study was found that Urban and Rural college students significant differences from Perception of Reality. The findings of the supported the hypothesis, they are hypothesis rejected the present study. Its means that Rural College Students high Perception of Reality than Urban College Students.

Table No.03 Show the mean, SD and F value
Living of Area on Integration of Personality
\begin{tabular}{|c|c|c|c|c|c|c|}
\hline Location & Mean & SD & N & DF & F & Sign \\
\hline $\begin{array}{c}\text { Urban } \\
\text { Students }\end{array}$ & 28.14 & 5.89 & 50 & & & \\
$\begin{array}{c}\text { Rural } \\
\text { Students }\end{array}$ & 28.42 & 4.73 & 50 & & & \\
\hline
\end{tabular}

(Critical value of "f" with df 98 at $0.01=3.94$ and at $0.05=6.90$ and NS-Not significant)

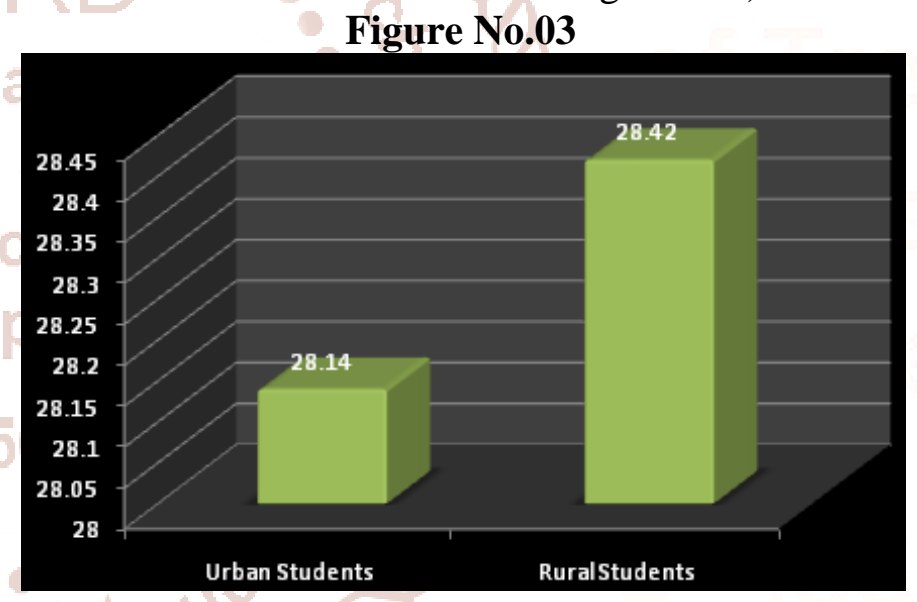

Observation of the table No.03 and Figure No.03 indicated that the mean value of two classified group seems to differ from each other on Integration of Personality. The mean and SD value obtained by the Urban college students 28.14, SD 5.89 and Rural College students was 28.42, SD 4.73, Both group ' $F$ ' ratio was 0.80 at a glance those Rural college student shows miner high score than Urban college students.

In the present study was hypothesis related Integration of Personality and Living of Area. It was "There is no significant differences between Urban and Rural college students with Mental Health dimension on Integration of Personality. Living of Area effect represent the Integration of Personality was not significant ((F- 0.80, 1and 99, P-NS). This is not significant 0.01 and 0.05 levels because they obtained 
' $F$ ' value are low than table values at 0.01 and 0.05 . In the present study was found that Urban and Rural college students not significant differences from Integration of Personality. The findings of the supported the hypothesis, they are hypothesis Accepted the present study. I03ts means that there is no significant difference between Urban and Rural College students with Mental Health dimension on Integration of Personality.

Table No.04 Show the mean, SD and F value
Living of Area on Autonomy
\begin{tabular}{|c|c|c|c|c|c|c|}
\hline Location & Mean & SD & N & DF & F & Sign \\
\hline $\begin{array}{c}\text { Urban } \\
\text { Students }\end{array}$ & 16.34 & 5.24 & 50 & & & \\
\hline $\begin{array}{c}\text { Rural } \\
\text { Students }\end{array}$ & 19.38 & 6.95 & 50 & & & \\
\hline
\end{tabular}

(Critical value of "f" with df 98 at $0.01=3.94$ and at $0.05=6.90$ and NS-Not significant)

\section{Figure No.04}

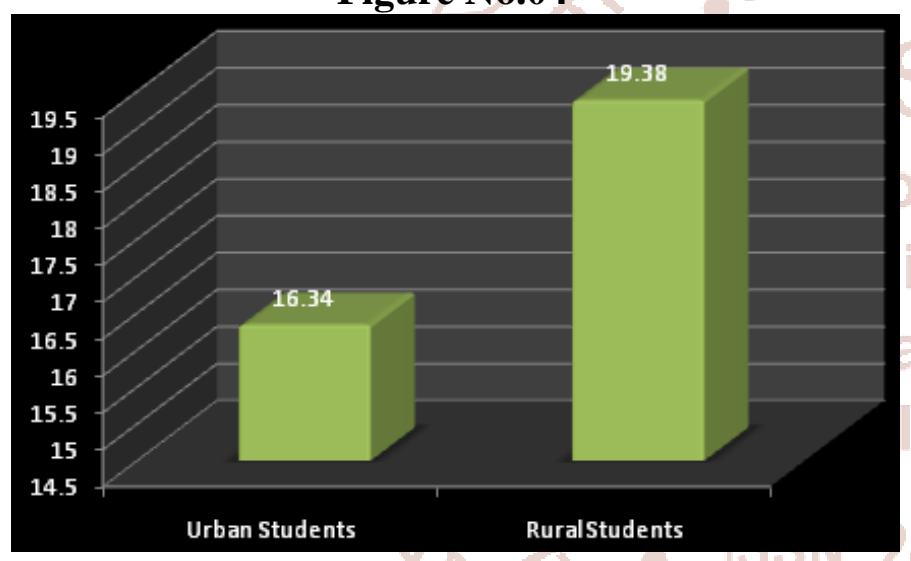

Observation of the table No.04 and Figure No.04 indicated that the mean value of two classified group seems to differ from each other on Autonomy. The mean and SD value obtained by the Urban college students 16.34, SD 5.24 and Rural College students was 19.38, SD 6.38, Both group ' $F$ ' ratio was 6.34 at a glance those Rural college student shows high score than Urban college students.

In the present study was hypothesis related Autonomy and Living of Area. It was "There is no significant differences between Urban and Rural college students with Mental Health dimension on Autonomy. Living of Area effect represent the Autonomy was significant ((F- 6.34, 1and 99, P-0.05). This is significant 0.05 levels because they obtained ' $F$ ' value are high than table values at 0.05 . In the present study was found that Urban and Rural college students significant differences from Autonomy. The findings of the not supported the hypothesis, they are hypothesis rejected the present study. Its means that Rural college Students high Autonomy than Urban College Students.

Table No.05 Show the mean, SD and F value
Living of Area on Group Oriented Attitudes
\begin{tabular}{|c|c|c|c|c|c|c|}
\hline Location & Mean & SD & N & DF & F & Sign \\
\hline $\begin{array}{c}\text { Urban } \\
\text { Students }\end{array}$ & 24.46 & 5.41 & 50 & & & \\
\hline $\begin{array}{c}\text { Rural } \\
\text { Students }\end{array}$ & 23.30 & 7.52 & 50 & & & \\
\hline
\end{tabular}

(Critical value of "f" with df 98 at $0.01=3.94$ and at $0.05=6.90$ and NS-Not significant)

Figure No.05

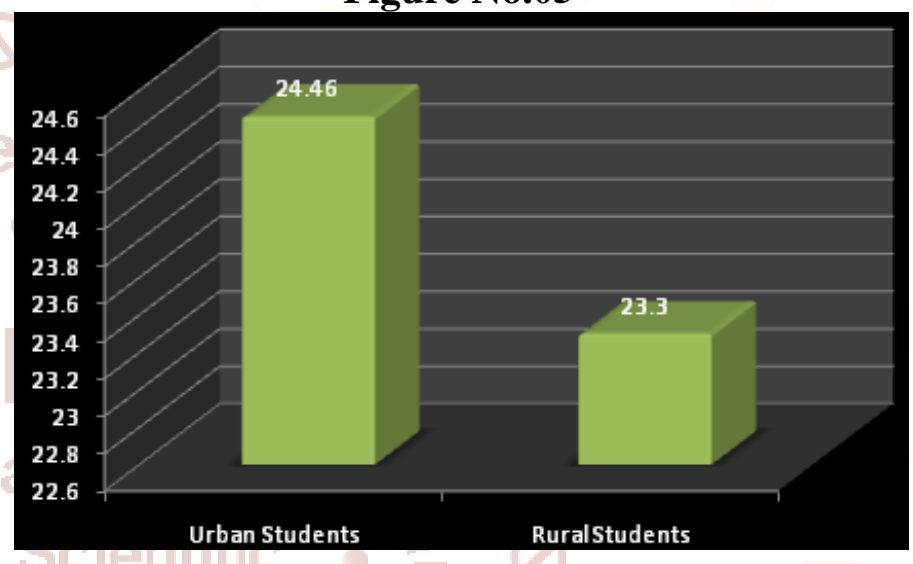

Observation of the table No.05 and Figure No.05 indicated that the mean value of two classified group seems to differ from each other on Group Oriented Attitudes. The mean and SD value obtained by the Urban college students 24.46, SD 5.41 and Rural College students was 23.30, SD 7.52, Both group ' $F$ ' ratio was 0.77 at a glance those Urban college student shows miner high score than Rural college students.

In the present study was hypothesis related Group Oriented Attitudes and Living of Area. It was "There is no significant differences between Urban and Rural college students with Mental Health dimension on Group Oriented Attitudes. Living of Area effect represent the Group Oriented Attitudes was not significant ((F- 0.77, 1and 99, P-NS). This is not significant 0.01 and 0.05 levels because they obtained ' $F$ ' value are low than table values at 0.01 and 0.05 . In the present study was found that Urban and Rural college students not significant differences from Group Oriented Attitudes. The findings of the supported the hypothesis, they are hypothesis Accepted the present study. I03ts means that there is no significant difference between Urban and Rural College students with Mental Health dimension on Group Oriented Attitudes. 
International Journal of Trend in Scientific Research and Development (IJTSRD) ISSN: 2456-6470

Table No.06 Show the mean, SD and F value

Living of Area on Environment Mastery

\begin{tabular}{|c|c|c|c|c|c|c|}
\hline Location & Mean & SD & N & DF & F & Sign \\
\hline $\begin{array}{c}\text { Urban } \\
\text { Students }\end{array}$ & 22.82 & 5.60 & 50 & & & \\
\hline $\begin{array}{c}\text { Rural } \\
\text { Students }\end{array}$ & 21.20 & 7.45 & 50 & 98 & 1.72 & NS \\
\hline
\end{tabular}

(Critical value of "f" with df 98 at $0.01=3.94$ and at $0.05=6.90$ and NS-Not significant)

\section{Figure No.06}

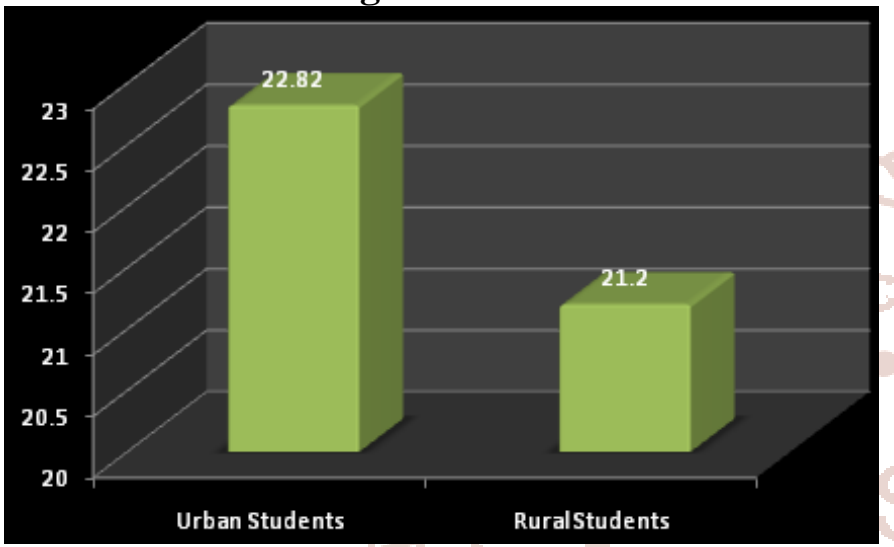

Observation of the table No.06 and Figure No.06 indicated that the mean value of two classified group seems to differ from each other on Environment Mastery. The mean and SD value obtained by the Urban college students 22.82, SD 5.60 and Rural College students was 21.20, SD 7.45, Both group ' $F$ ' ratio was 1.72 at a glance those Urban college student shows miner high score than Rural college students.

In the present study was hypothesis related Environment Mastery and Living of Area. It was "There is no significant differences between Urban and Rural college students with Mental Health dimension on Environment Mastery. Living of Area effect represent the Environment Mastery was not significant $((\mathrm{F}-1.72$, 1and 99, P-NS). This is not significant 0.01 and 0.05 levels because they obtained ' $F$ ' value are low than table values at 0.01 and 0.05 . In the present study was found that Urban and Rural college students not significant differences from Environment Mastery. The findings of the supported the hypothesis, they are hypothesis Accepted the present study. Its means that there is no significant difference between Urban and Rural College students with Mental Health dimension on Environment Mastery.
Table No.07 Show the mean, SD and $F$ value Living of Area on Mental Health

\begin{tabular}{|c|c|c|c|c|c|c|}
\hline Location & Mean & SD & N & DF & F & Sign \\
\hline $\begin{array}{c}\text { Urban } \\
\text { Students }\end{array}$ & 136.80 & 22.55 & 50 & & & \\
\hline $\begin{array}{c}\text { Rural } \\
\text { Students }\end{array}$ & 141.84 & 17.61 & 50 & 98 & 1.67 & NS \\
\hline
\end{tabular}

(Critical value of "f" with df 98 at $0.01=3.94$ and at $0.05=6.90$ and NS-Not significant)

\section{Figure No.07}

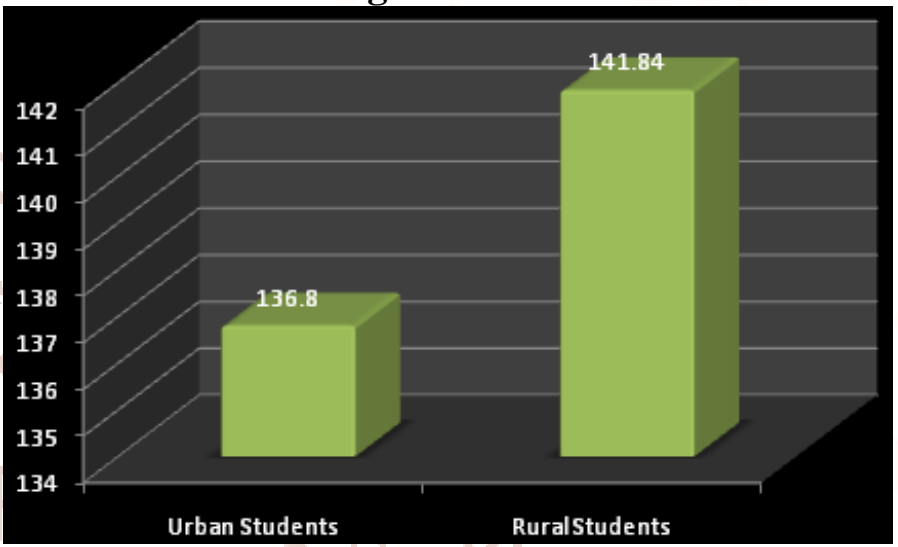

Observation of the table No.07 and Figure No.07 indicated that the mean value of two classified group seems to differ from each other on Mental Health. The mean and SD value obtained by the Urban college students 136.80, SD 22.55 and Rural College students was 141.84 , SD 17.61, Both group ' $F$ ' ratio was 1.67 at a glance those Rural college student shows miner high score than Urban college students.

In the present study was hypothesis related Mental Health and Living of Area. It was "There is no significant difference between Urban and Rural college students on Mental Health. Living of Area effect represent the Mental Health was not significant ((F-1.67, 1and 99, P-NS). This is not significant 0.01 and 0.05 levels because they obtained ' $F$ ' value are low than table values at 0.01 and 0.05 . In the present study was found that Urban and Rural college students not significant differences from Mental Health. The findings of the supported the hypothesis, they are hypothesis Accepted the present study. I03ts means that there is no significant difference between Urban and Rural College students on Mental Health.

\section{Delimitations of the study}

1. The finding of the study is based on very sample.

2. The sample was restricted to Ambad city from Jalna Dist. in Maharashrta. 
3. The study was restricted to only B.A. arts college students (arts facility) only.

4. The study was restricted students are only 18-21 years only.

\section{Conclusions:}

1. There is no significant difference between Urban and Rural College students with Mental Health dimension on Positive self Evaluation.

2. Rural College Students high Perception of Reality than Urban College Students.

3. There is no significant difference between Urban and Rural College students with Mental Health dimension on Integration of Personality.

4. Rural college Students high Autonomy than Urban College Students.

5. There is no significant difference between Urban and Rural College students with Mental Health dimension on Group Oriented Attitudes.

6. There is no significant difference between Urban and Rural College students with Mental Health dimension on Environment Mastery.

7. There is no significant differences between Male and Female college students on Mental Health.

\section{REFERENCES}

1. Bangale, Jaya and Patnam, Vishala (2014). Mental health of undergraduate students and its influencing factors. Internat. J. Med. Sci., 7(1 \& 2) : 38-42.

2. Jagadish, S. and Srivastava, A. K., 1983, Manual for mental health inventory, published by manovaigyanik parikshan sansthan, Varanasi.

3. Jahoda, M. (1958). Current Concepts of Positive Mental Health. New York: Basic Books.
4. Kaplan, L. (1971). Education and Mental Health. New York; Harper and Row Pub.

5. Morab

A. H., Yadav V. S. And. Khadi P. B.,(2014) Mental health of rural elderly, Karnataka J. Agric. Sci.,27 (3): 330-332.

6. Murray, C. L., Gein, I. and Solber g, M., 2003, A comparison of the mental health of employed and unemployed women in the context of a massive layoff f. W omen and health, 37(2): 55-72.

7. Ojha, S. and Rani, U., 2004, A comparative study of the level of life stress and various dimension of mental health among working and non-working Indian women. J. com. Guid. Res., 21(3):297-303.

8. Ray, V.K. and Yadav, V.C. (1993). A study of mental health of higher secondary students in relation to socio-economic status. J. Psych. Res., 37(182): 39-46.

9. Vijay Kumar, Pawan Kumar and Reena Kumari, ( Nov.2013), Study Of Mental Health Of Pupil Teachers In Relation To Their Gender And Locality; Abhinav- Journal of Research In Management \& Technology, vol. II, 104-110.

10. WHO (2001). Basic documents. 43rd Edition. World Health Organization:1, Geneva.

11. WHO (2001). Strengthening mental health promotion. World Health Organization (Fact sheet, No. 220), Geneva.

12. WHO (2004). Promoting mental health: concepts, emerging evidence, practice (Summary Report). World Health Organization, Geneva.

13. World Health Organization (1994). The health of young people: A challenge and a promise. Geneva, WHO. 